\title{
An Uncommon Procedure for a Rare Ailment: Massive Bronchoalveolar Lavage in a Patient with Pulmonary Alveolar Proteinosis
}

\author{
Hilal Günal Sazak', Şaziye Şahinn', Polat Pehlivanoğlu', Özlem Çakır ${ }^{1}$, Mehtap Tunç${ }^{1}$, Fatma Ulus ${ }^{1}$, Behiye Akkalyoncu², \\ Belgin Samurkaşoğlu²
}

'Department of Anesthesiology and Reanimation, Atatürk Chest Disease and Thoracic Surgery Education and Research Hospital, Ankara, Turkey ${ }^{2}$ Department of Chest Disease and Tuberculosis, Atatürk Chest Disease and Thoracic Surgery Education and Research Hospital, Ankara, Turkey

\begin{abstract}
As a rare procedure, massive bronchoalveolar lavage (MBAL) is a large-volume lavage which necessitates general anesthesia and one-lung ventilation (OLV). During MBAL isotonic saline is instilled into one lung and drained through one lumen of a double-lumen tube. MBAL is the most effective treatment for symptomatic pulmonary alveolar proteinosis (PAP). A 27-year-old male with PAP was scheduled for therapeutic MBALs. After standard preoxygenation, monitoring and anesthesia induction, a double-lumen tube was placed. Tube position was verified by a fiberoptic bronchoscope. The internal jugular vein, radial and pulmonary arteries were cannulated. A temperature probe and foley catheter were inserted. The nonventilated lung was filled with $1000 \mathrm{~mL}$ saline and then drained in each session. The left and right lung were lavaged with an interval of 2 weeks. A total of $20 \mathrm{~L}$ saline was used in each MBAL without retention. MBALs were terminated after the effluent became clear. Duration of the left and right MBALs were 325 and 275 minutes, respectively. Despite increased shunt fraction, oxygenation was within acceptable limits during OLV. The trachea was extubated in the operating room uneventfully after each MBAL. The patient's clinical and laboratory findings were evidently improved. Consequently, if proper conditions are provided, $M B A L$ is safe and beneficial despite its risks and the long duration.
\end{abstract}

Key Words: Bronchoalveolar lavage, pulmonary alveolar proteinosis, general anesthesia

Received: 04.04.2012 Accepted: 05.06.2012

\section{Introduction}

Bronchoalveolar lavage (BAL) is usually used to evaluate the inflammatory response in anesthesia researches (1). However, we reported an uncommon and unique procedure, therapeutic massive BAL (MBAL), in a patient with pulmonary alveolar proteinosis (PAP). PAP is a rare and diffuse lung disease in which alveolar accumulation of periodic acid Schiff positive phospholipid materials occurs with preservation of the septal architecture of the lung interstitium (2). PAP, with an estimated annual prevalence of 3.7 cases per million population (3), was described in 1958 (2). MBAL has been used for removal of alveolar filling material in conditions such as PAP, alveolar microlithiasis, acute silicosis, cystic fibrosis and inhalation of radioactive particles $(4,5)$. From $54 \%$ to $75 \%$ of patients with PAP undergo at least one lavage procedure (6). MBAL is the most effective treatment method for symptomatic PAP (5). During MBAL, a large-volume isotonic saline is instilled into one lung and then drained through one lumen of a double- lumen tube (DLT). Therefore, therapeutic MBAL, which is one of the absolute indications for one-lung ventilation (OLV), is performed under general anesthesia (4). A major concern that affects anesthetic management is the occurrence of hypoxemia during OLV (5). MBAL is expected to be associated with an increased risk of hypoxemia in a patient with PAP and the requirement of long-term OLV (7). However, data including intrapulmonary shunt fraction during MBAL is very scarce in the literature (8). In this report, we aim to share our experiences on the management of anesthesia, monitoring and MBAL.

\section{Case Report}

A 27 year-old nonsmoker man, $72 \mathrm{~kg}$ and $175 \mathrm{~cm}$ tall, was diagnosed as PAP with open lung biopsy previously. The sequential left and right-sided therapeutic MBAL were planned, respectively, because of progressive hypoxemia and shortness of breath on exertion. In the preanesthetic assessment of the patient who had no other medical problem, the results of certain laboratory tests deteriorated. Chest radiograph showed bilateral and symmetric patchy consolidation of air spaces (Figure 1). Pulmonary function tests (PFT) reflected a restrictive ventilatory defect with a reduction in diffusion capacity. The results of arterial blood gases (ABG) analysis, PFT and diffusing capacity of the lung for carbon monoxide $\left(D_{1} C O\right)$ were included in Table 1.

After premedication with midazolam, electrocardiogram, heart rate, blood pressure and peripheral oxygen saturation $\left(\mathrm{SpO}_{2}\right)$ were monitored in the operating room 
Table 1. Arterial blood gases, pulmonary function tests and diffusing capacity of the lung for carbon monoxide prior to and after the left and right-sided MBAL

\begin{tabular}{|c|c|c|c|}
\hline & Prior to MBALs & After left MBAL & After right MBAL \\
\hline $\mathrm{pH}$ & 7.39 & 7.36 & 7.41 \\
\hline $\mathrm{PaCO}_{2}(\mathrm{~mm} \mathrm{Hg})$ & 39.1 & 36.5 & 35 \\
\hline $\mathrm{PaO}_{2}(\mathrm{~mm} \mathrm{Hg})$ & 57.5 & 65.2 & 83 \\
\hline FVC (L) & $2.6(53 \%)$ & $3.06(60 \%)$ & $3.48(68 \%)$ \\
\hline $\mathrm{FEV}_{1}(\mathrm{~L})$ & $2.1(49 \%)$ & $2.49(58 \%)$ & $2.80(65 \%)$ \\
\hline $\mathrm{FEV}_{1} / \mathrm{FVC}(\%)$ & $79 \%$ & $81 \%$ & $80 \%$ \\
\hline DLCO (mm Mol/kPa.min) & $45 \%$ & $61 \%$ & $70 \%$ \\
\hline
\end{tabular}

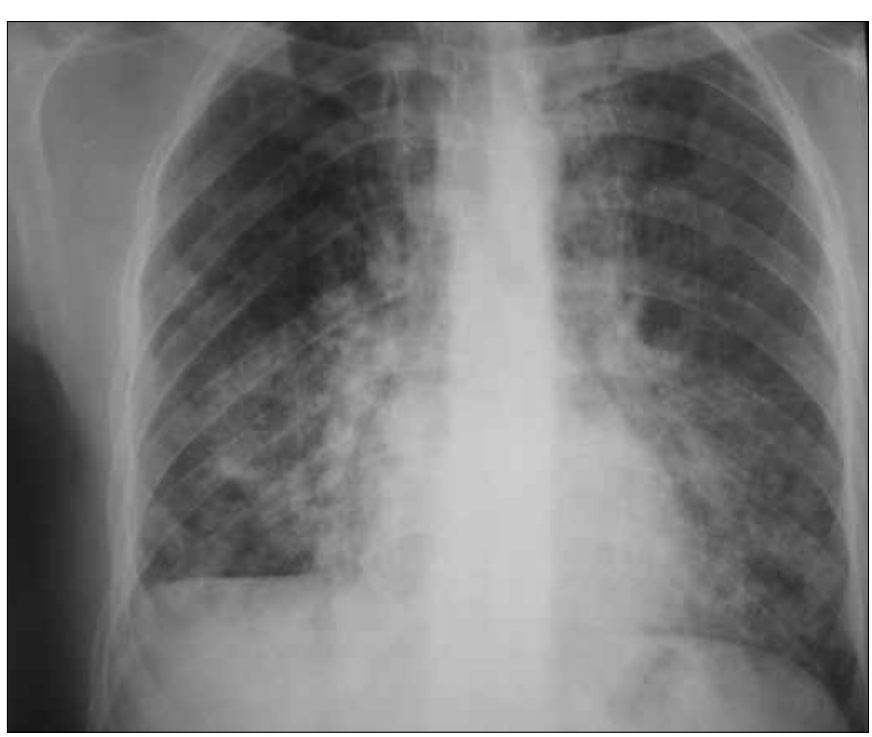

Figure 1. Chest radiograph showing bilateral and symmetric patchy consolidation of air spaces

for the anesthetic process of sequential left and right-sided MBAL. Following preoxygenation, general anesthesia was induced with fentanyl, propofol and cisatracurium (vecuronium for right-sided MBAL). A 41 Fr left-sided Robertshaw DLT (Rüsch ${ }^{\circledR}$, Germany) was placed and controlled with the conventional method. The correct position of the DLT was also periodically confirmed by a fiberoptic bronchoscope (Olympus $^{\circledR}$ LF-GP, Japan) during the procedure. The right internal jugular vein, radial and pulmonary artery were cannulated. Invasive arterial pressure, end-tidal $\mathrm{CO}_{2}(\mathrm{ET} \mathrm{CO}), \mathrm{ABG}$, body temperature and urine output were monitored. Simultaneously collected arterial and mixed venous blood gases were used for calculation of the intrapulmonary shunt fraction ( $\mathrm{Qs}$ ) Qt) with the standard equation. Desflurane (sevoflurane for right-sided $\mathrm{MBAL}$ ) in 100\% oxygen, fentanyl and cisatracurium (vecuronium for right-sided $M B A L$ ) were used in the maintenance of anesthesia. An adequate degree of neuromuscular blockade was maintained to prevent unexpected coughing during the procedure. The patient was kept in the supine position throughout the procedure. Tidal volume was conducted as $6 \mathrm{~mL} / \mathrm{kg}$ for OLV whereas this was $8 \mathrm{~mL} / \mathrm{kg}$ for double-lung ventilation. OLV was instituted with the nonlavaged lung and $5 \mathrm{~cm} \mathrm{H} \mathrm{H}_{2} \mathrm{O}$ positive end-expiratory pressure (PEEP) was added to the tidal volume. Respiratory rate was adjusted to maintain $\mathrm{ET} \mathrm{CO}_{2}$ in the range of $30-35 \mathrm{~mm} \mathrm{Hg}$. Compliance of the ventilated lung and the shunt fraction were also presented together with the other ventilatory and hemodynamic parameters measured during MBALs (Table 2 and 3). Shunt fraction values belonged to the phases of drainage because the arterial and mixed venous blood gases were only collected at these times. There were transient declines (1-2\%) in $\mathrm{SpO}_{2}$ during sessions of drainage compared to filling periods.

The management of MBALs was as follows: the nonventilated, lavaged, lung was filled with warmed isotonic saline $\left(37^{\circ} \mathrm{C}\right)$. A disposable, Y-shaped irrigation and drainage set with the length of $150 \mathrm{~cm}$ was used for lavage. In every filling period, $1000 \mathrm{~mL}$ saline was infused by gravity into one lung from a height of $50 \mathrm{~cm}$ above the carina. A warming blanket was placed over the patient during the procedure. After each filling session, by clamping the inflow line and unclamping the other, saline was rapidly drained by gravity into a container. This process was repeated until effluent lavage fluid became clear, when MBAL was terminated. Manual chest percussion was performed to the lavaged hemithorax during filling and drainage in order to maximize them. The operating room table was placed in head-down position to facilitate removal of lavage fluid. The lavage volumes, administered and drained, were recorded carefully at each session. A total of $20 \mathrm{~L}$ isotonic saline was used during each MBAL without retention of fluid. At the end of the procedures the lavaged lung was suctioned, and inflation of both lungs was accomplished. Residual neuromuscular block was reversed. Durations of the procedures were 325 and 275 minutes, respectively. The patient was hemodynamically stable throughout the procedure. After uneventful extubation in the operating room, he was monitored in the intensive care unit (ICU) for 24 hours. In ICU, chest wall percussion to the lavaged side and breathing exercises were used to remove secretion and re-expand alveoli. After recovery, he was transferred to the ward. The ABG, PFT and $D_{L} C O$ values collected in the ward were seen in Table 1 . The chest radiograph obtained after MBALs was represented in Figure 2. 
Table 2. Ventilatory and hemodynamic parameters during steps of left-sided MBAL

\begin{tabular}{|c|c|c|c|c|c|c|c|c|c|c|c|}
\hline & pre & $\mathrm{DLV}^{1}$ & OLV & 1. L & 3. L & 5. L & 10. L & 15. L & 20. L & $\mathrm{DLV}^{2}$ & rec \\
\hline $\mathrm{pH}$ & 7.39 & 7.38 & 7.34 & 7.32 & 7.35 & 7.34 & 7.32 & 7.3 & 7.33 & 7.26 & 7.37 \\
\hline $\mathrm{PaCO}_{2}(\mathrm{~mm} \mathrm{Hg})$ & 39.1 & 37 & 42.7 & 44.4 & 41.5 & 40.9 & 43.8 & 45.6 & 40.4 & 45.5 & 35 \\
\hline $\mathrm{PaO}_{2}(\mathrm{~mm} \mathrm{Hg})$ & 57.5 & 285.4 & 92.8 & 87.9 & 70.5 & 84.8 & 96.2 & 106.9 & 93 & 143 & 97 \\
\hline $\mathrm{SpO}_{2}(\%)$ & 93 & 97 & 94 & 94 & 93 & 96 & 97 & 97 & 97 & 98 & 98 \\
\hline $\mathrm{ET} \mathrm{CO}{ }_{2}(\mathrm{~mm} \mathrm{Hg})$ & - & 30 & 32 & 31 & 29 & 28 & 30 & 34 & 31 & 30 & - \\
\hline Compliance & - & 39.9 & 21.6 & 26.8 & 24 & 25.2 & 24.4 & 25.4 & 20.9 & 42 & - \\
\hline HR (beat/min) & 73 & 74 & 81 & 75 & 73 & 72 & 77 & 86 & 92 & 90 & 108 \\
\hline MAP (mm Hg) & 83 & 67 & 74 & 65 & 75 & 78 & 71 & 72 & 68 & 102 & 84 \\
\hline CVP $(\mathrm{mm} \mathrm{Hg})$ & - & 3 & 2 & 3 & 3 & 7 & 9 & 10 & 7 & 8 & 4 \\
\hline MPAP (mm Hg) & - & 12 & 14 & 14 & 15 & 17 & 20 & 23 & 18 & 16 & - \\
\hline PCWP (mm Hg) & - & 8 & 6 & 8 & 9 & 13 & 15 & 13 & 12 & 13 & - \\
\hline Temperature $\left({ }^{\circ} \mathrm{C}\right)$ & - & 36.6 & 36.1 & 35.6 & 35.6 & 35.2 & 35.5 & 36.1 & 36.3 & 36.5 & - \\
\hline Os / Qt (\%) & - & 17.9 & 36 & 35.9 & 42 & 34.8 & 33 & 36.3 & 37.2 & 32.1 & - \\
\hline
\end{tabular}

Table 3. Ventilatory and hemodynamic parameters during steps of right-sided MBAL

\begin{tabular}{|c|c|c|c|c|c|c|c|c|c|c|c|}
\hline & pre & DLV $^{1}$ & OLV & 1. $L$ & 3. $L$ & 5. L & 10. L & 15. L & 20. L & DLV $^{2}$ & rec \\
\hline $\mathrm{pH}$ & 7.36 & 7.35 & 7.31 & 7.34 & 7.34 & 7.33 & 7.36 & 7.38 & 7.35 & 7.33 & 7.38 \\
\hline $\mathrm{PaCO}_{2}(\mathrm{~mm} \mathrm{Hg})$ & 36.5 & 42.5 & 47 & 43.3 & 43.1 & 46 & 41.3 & 36.3 & 38 & 40.3 & 30.3 \\
\hline $\mathrm{PaO}_{2}(\mathrm{~mm} \mathrm{Hg})$ & 65.2 & 143.2 & 95.4 & 67.1 & 75.5 & 89.3 & 143.6 & 99.8 & 119.4 & 117.6 & 85.9 \\
\hline $\mathrm{SpO}_{2}(\%)$ & 93 & 98 & 96 & 95 & 96 & 99 & 98 & 98 & 97 & 97 & 94 \\
\hline $\mathrm{ET} \mathrm{CO}_{2}(\mathrm{~mm} \mathrm{Hg})$ & - & 37 & 37 & 31 & 32 & 32 & 30 & 30 & 30 & 26 & - \\
\hline Compliance & - & 37.8 & 31.6 & 33 & 25.2 & 29.5 & 30.4 & 29.6 & 29.8 & 35.6 & - \\
\hline HR (beat/min) & 74 & 73 & 88 & 90 & 88 & 82 & 82 & 88 & 88 & 94 & 120 \\
\hline $\mathrm{MAP}(\mathrm{mm} \mathrm{Hg})$ & 83 & 76 & 65 & 62 & 78 & 81 & 73 & 72 & 69 & 65 & 72 \\
\hline CVP $(\mathrm{mm} \mathrm{Hg})$ & - & 4 & 1 & 2 & 7 & 11 & 11 & 9 & 4 & 2 & 7 \\
\hline MPAP (mm Hg) & - & 14 & 20 & 17 & 19 & 20 & 23 & 22 & 22 & 19 & - \\
\hline PCWP (mm Hg) & - & 15 & 22 & 18 & 22 & 25 & 20 & 21 & 18 & 18 & - \\
\hline Temperature $\left({ }^{\circ} \mathrm{C}\right)$ & - & 36.6 & 36.6 & 36.3 & 36.6 & 36.7 & 36.8 & 37 & 37 & 37.3 & - \\
\hline Os / Qt (\%) & - & 22 & 34.6 & 45.3 & 39.1 & 42.1 & 26.3 & 33.4 & 30.8 & 31.4 & - \\
\hline
\end{tabular}

\section{Discussion}

In this report, we presented a case who underwent successful MBALs, a challenging issue, under long-term one-lung anesthesia. Monitoring of temperature, hemodynamic parameters and $A B G$ during MBAL are essential for anesthesiologists (2). Webb et al. (9) recommended multidisciplinary team work, lung separation with a left-sided DLT, OLV with PEEP, ventilatory monitoring, careful use of positional maneuvers and use of preoxygenation in patients with PAP. Preoxygenation prior to anesthesia induction is needed in such cases (10). Preoxygenation is useful for both minimal risk of hypoxemia and effectiveness of the lavage by removing nitrogen from the lung (5). To avoid dangerous hypothermia the temperature of saline must be $35-37.5^{\circ} \mathrm{C}$ during the procedure (2).
Lavage itself has caused no significant changes in systemic and pulmonary arterial pressures (5). However, filling of the lung with massive volumes can cause sudden hemodynamic changes such as increase in intrathoracic pressure, mediastinal shift and cessation of blood flow to the lavaged lung (11). In our case, hemodynamic instability, hypoxemia and hypothermia were avoided with the aid of careful monitoring. Although central venous, mean pulmonary arterial and capillary wedge pressures tended to increase during procedures, these values were within tolerable limits.

Nowadays, acute lung injury is another important problem along with the existence of hypoxemia during OLV (12). Lung protective ventilation strategies are recommended to avoid acute lung injury related to high tidal volume, inspiratory pressures and volutrauma (13). In the present case, 


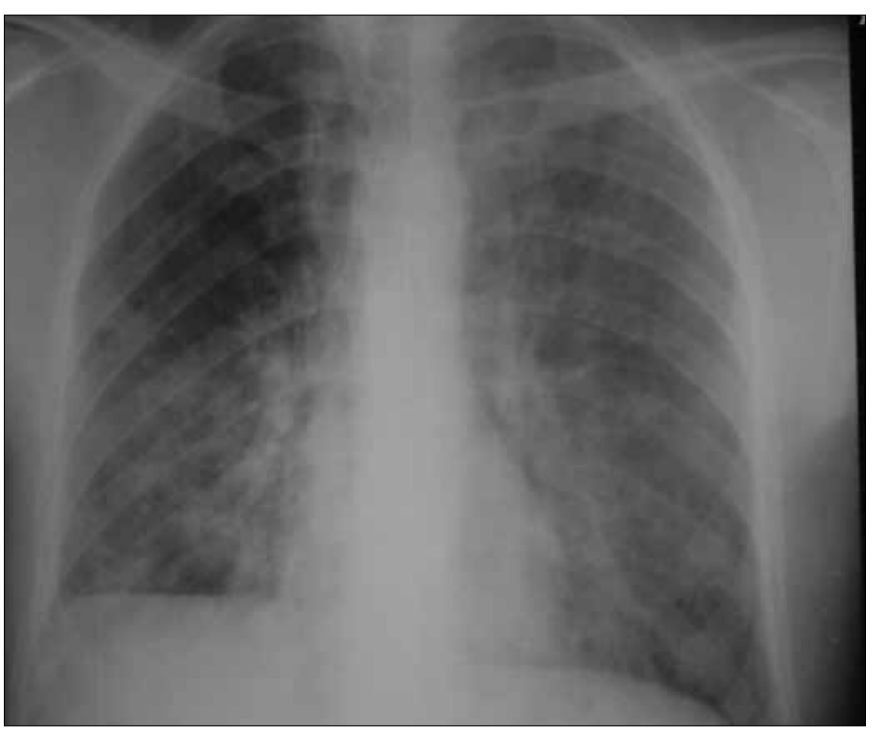

Figure 2. Chest radiograph obtained after MBALs

we also applied low tidal volume with PEEP and $100 \%$ oxygen during OLV. Peak airway pressures were under $35 \mathrm{~cm}$ $\mathrm{H}_{2} \mathrm{O}$ during OLV. Emptying of the lung can impair pulmonary gas exchange because the shunt increases (8). We observed slight and transient declines in $\mathrm{SpO}_{2}$ during sessions of drainage. Temporary decrease in $\mathrm{SpO}_{2}$ resulted from increased blood flow in the lavaged lung during the drainage phase $(5,10)$. Similar to the results of Moutafis et al. (8), shunt fractions increased slightly during some periods of drainage compared to OLV without lavage. In spite of increased shunt fraction, arterial oxygenation was within acceptable limits during OLV. Ventilation and oxygenation were adequate in the course of ICU and the ward. The satisfactory oxygenation was attributed to successful separation of the two lungs and management of OLV in our case. Criteria for $\mathrm{MBAL}$ are, $\mathrm{PaO}_{2}$ less than $60 \mathrm{~mm} \mathrm{Hg}$ at rest or hypoxemic limitation of normal activity $(5,10)$. The position of the patient is important and may be either lateral decubitus or supine during MBAL (4, 10). Each position has advantages and disadvantages. The disadvantage of the lateral decubitus position with the lavaged lung nondependent is the risk of spillage of lavage fluid to the ventilated lung. On the other hand, decreased blood flow to the nonventilated lung is the advantage. The lateral decubitus position with lavaged lung dependent has the disadvantage of increased blood flow to the nonventilated lung during periods of lavage fluid drainage. However, a minimal possibility of spillage to the ventilated lung is its advantage $(5,10)$. We preferred the supine position which has the balanced risk of aspiration with the risk of hypoxemia in the procedures. MBAL has complications such as hydropneumothorax, bronchospasm and pneumonia (4). Pneumothorax, pleural effusion and spillage of lavage fluid into the contralateral (ventilated) lung may also occur (14). We used continuous monitoring of the pulmonary compliance of the ventilated lung and observation of lavage fluid with regard to air bubbles to diagnose any liquid spillage from the lavaged lung. The observed definite decrease in the compliance of the ventilated lung was the result of OLV itself. Sudden de- crease of $\mathrm{SpO}_{2}$, appearance of bubbles in lavage fluid and failure of drainage might be signs of incomplete separation of the two lungs. Therefore, the position of the DLT should be rechecked by fiberoscopy (10). In this case, DLT displacement and flooding of the nonlavaged lung were prevented by periodical fiberoptic bronchoscopies during the procedures. The retention of $500-1500 \mathrm{~mL}$ lavage fluid was reported in previous cases (2). Manual percussion and positional drainage are used to improve the removal of surfactant during lavage $(15,16)$. In the present case, there was no retention of saline after both MBALs. This was attributed to continuous chest percussion applied during phases of MBALs.

\section{Conclusion}

Massive BAL should be considered in the treatment of selected patients with PAP as long as adequate preparation is accomplished, and proper conditions are provided. In a patient with PAP, PFT and ABG can be used to assess the response to treatment (15). Considering the marked improvements in clinical and laboratory findings in the present case, MBAL was beneficial. Although lung protective ventilation did not prevent the elevation in shunt fraction during OLV, adequate oxygenation was provided. With the avoidance of hemodynamic instability, hypoxemia and hypothermia, MBAL performed by an experienced team is safe and efficient despite its risks and long duration.

\section{Acknowledgement}

We thank ibrahim Öner for his kind contributions in revision of the language of this article.

\section{Conflict of Interest}

No conflict of interest was declared by the authors.

\section{References}

1. Erol A, Reisli R, Reisli i, Otelcioğlu Ş. The effects of sevoflurane, desflurane and propofol on the percentages and activation molecules of the lymphocytes: A flow cytometry analysis of bronchoalveolar lavage fluid. Turkiye Klinikleri J Med Sci 2011;31:443-9. [CrossRef]

2. Claypool WD, Rogers RM, Matuschak GM. Update on the clinical diagnosis, management, and pathogenesis of pulmonary alveolar proteinosis (phospholipidosis). Chest 1984;85:550-8. [CrossRef]

3. Ben-Dov I, Kishinevski Y, Roznman J, Soliman A, Bishara H, Zelligson $E$, et al. Pulmonary alveolar proteinosis in Israel: ethnic clustering. Isr Med Assoc J 1999;1:75-8.

4. Danel C, Israël-Biet D, Costabel U, Klech H. Therapeutic applications of bronchoalveolar lavage. Eur Respir J 1992;5:1173-5.

5. Benumof JL, Alfery DD. Anesthesia for thoracic surgery. In: Miller RD (ed). Anesthesia. 5th ed. Philadelphia: Churchill Livingstone, 2000;1665-752.

6. Mazzone $\mathrm{P}$, Thomassen MJ, Kavuru M. Our new understanding of pulmonary alveolar proteinosis: what an internist needs to know. Cleve Clin J Med 2001;68:977-93. [CrossRef]

7. Dixit R, Chaudhari LS, Mahashur AA. Anaesthetic management of bilateral alveolar proteinosis for bronchopulmonary lavage. $J$ Postgrad Med 1998;44:21-3.

8. Moutafis M, Dalibon N, Colchen A, Fischler M. Improving oxygenation during bronchopulmonary lavage using nitric oxide inhalation and almitrine infusion. Anesth Analg 1999;89:302-4. [CrossRef] 
9. Webb ST, Evans AJ, Varley AJ, Klein AA. Anaesthesia for serial whole-lung lavage in a patient with severe pulmonary alveolar proteinosis: a case report. J Med Case Rep 2008;2:360. [CrossRef]

10. Benumof JL. Anesthesia for special elective therapeutic procedures. In: Benumof JL, ed. Anesthesia for Thoracic Surgery. 2nd ed. Philadelphia: W.B. Saunders Company, 1995; p. 548-55.

11. Swenson JD, Astle KL, Bailey PL. Reduction in left ventricular filling during bronchopulmonary lavage demonstrated by transesophageal echocardiography. Anesth Analg 1995;81:634-7. [CrossRef]

12. Lohser J. Evidence-based management of one-lung ventilation. Anesthesiol Clin 2008;26:241-72. [CrossRef]
13. Grichnik KP, Clark JA. Pathophysiology and management of onelung ventilation. Thorac Surg Clin 2005;15:85-103. [CrossRef]

14. Michaud G, Reddy C, Ernst A. Whole-lung lavage for pulmonary alveolar proteinosis. Chest 2009;136:1678-81. [CrossRef]

15. Shah PL, Hansell D, Lawson PR, Reid KB, Morgan C. Pulmonary alveolar proteinosis: clinical aspects and current concepts on pathogenesis. Thorax 2000;55:67-77. [CrossRef]

16. Sazak HG, Göktaş U, Alagöz A, Gülhan M, Şahan L, Şavkılıoğlu E, et al. Anesthesic management of whole lung lavage in pulmonary alveolar proteinosis (Case Report). Journal of Cardio-VascularThoracic Anaesthesia and Intensive Care Society 2003;9:77-81. 